\title{
OPEN SYLLABLE LENGTHENING IN MIDDLE ENGLISH: TWO-PROSODIC-PLANE THEORY
}

\author{
KeIKo Kaminashi \\ Tsuda College
}

\begin{abstract}
This paper is an attempt to explain the mechanism of Open Syllable Lengthening in Middle English, which is regarded as a Compensatory Lengthening process, within the framework of what we may call 'TwoProsodic-Plane Theory'. The notion, Minimal Word, was first proposed by McCarthy \& Prince 1986, 1988 in Prosodic Morphology. We will propose that the occurrences of OSL follow from the Minimal Foot Principle and the Minimal Word Principle which operate on the grid plane and on the syllable plane respectively. In doing so, we will reveal the general properties of CL processes, considering the grid constituent structures, Metrical and Syllable Transformations and the relationship between the grid plane and the syllable plane in Quantity Sensitive languages.*
\end{abstract}

\section{INTRODUCTION}

1.1. Preliminary. Open Syllable Lengthening $(\mathrm{OSL})^{1}$ in Middle English (ME) is a phonological process in which short vowels in open syllables with primary stress are lengthened in disyllabic words, ${ }^{2}$ as follows:

* This is the revised version of the papers I read at the Ninth International Conference on Historical Linguistics at Rutgers University on August 15, 1989 and at the Ninth Meeting of the Circle of Phonological Studies in Japan at Kobe University on November 18, 1989. I would like to express my deepest gratitude to Professor Toshio Nakao for invaluable questions, comments and suggestions on earlier versions of this paper. Thanks are also due to Professors Michael Hammond, Haruo Kubozono; John McCarthy, Donka Minkova, and Norio Yamada for valuable questions and comments. I would like to thank the audience of the conference and of the meeting as well. Thanks also go to Margaret Bowen and Kimberly DaSilva for correcting stylistic inconsistencies in this paper. I am also grateful to two anonymous reviewers for invaluable questions, comments and suggestions on an earlier version of this paper. Needless to say, any inadequacies are my own.

1 OSL contains a problem as to the quality of lengthened vowels, concerning which see Nakao \& Terajima 1982, among others. Suffice it to say here that lengthened vowels are lower than the input vowels by one degree in vowel height and that $/ \bar{e} / \mathrm{and}$ $\overline{\overline{0}} /$ are higher than $/ \overline{\bar{c} /} /$ and $/ \overline{\bar{Q}} /$ by one degree.

${ }^{2}$ Under some condition, OSL may take place in polysyllabic words as well, as given in fn. 29.

English Linguistics 7 (1990) 165-187 -165-

(C) 1990 by the English Linguistic Society of Japan 
(1) a. OSL of non-high vowels

$$
\begin{array}{ll}
\text { mete }>\text { męte 'meat' } & \text { efes }>\text { ęves 'eaves' } \\
\text { nose }>\text { nōse 'nose' } & \text { open }>\bar{q} \text { pen 'open' } \\
\text { nama }>\text { nāme 'name' } & \text { tacan }>\text { tāken 'take' } \\
\text { b. OSL of high vowels (Only in the North) } \\
\text { wiku }>\text { wẹ̄ke 'week' } & \text { gifes }>\text { gẹves 'gives' } \\
\text { duru }>\text { dọ̄re 'door' } & \text { cuman }>\text { cọme 'come' }
\end{array}
$$

In this paper, the following three questions as to OSL will be raised:

(2) (i ) What is the trigger of OSL?

(ii) Does the occurrence of OSL follow from some principle?

(iii) Why are there exceptions to OSL?

In answering these questions we will attempt to explain the mechanism of OSL, or more generally of Compensatory Lengthening (henceforth $\mathrm{CL})$ processes, within the framework which we may call 'Two-ProsodicPlane Theory'.

1.2. Previous analyses. A good deal of studies have been made as to OSL in ME. Cf. Nakao \& Terajima 1982, Nakao 1985 and works cited there. Among those phonologists, Grundt 1976 insightfully proposes that the reduction of the second syllable induces OSL, quoting Lehiste's 1970 proposal that disyllabic words, CVCV, exist as a phonological unit by means of duration ratios. In Grundt's analysis, however, the relationship between stress and prosodic structures is not considered.

In what follows, we will review the previous analyses of OSL in nonlinear phonology and point out problems that remain unsolved.

1.2.1. FoOT-BASED APPROACH-MINKOVA 1982, 1985. In order to explain OSL, Minkova makes use of the prosodic unit, the foot, which tends to be constructed maximally (Hayes 1980/1) and which is regarded as an isochronous unit. On the assumption that schwa loss precedes OSL, Minkova explains as follows:

(3) The metrical representation... shows that once the balance of the pre-OSL foot has been tampered with by schwa loss, an adjustment is effected on the peak node [i.e. nucleus in the syllable]. (Minkova 1985: 171)

In contrast, we will insist that the principles of maximality and isochrony should be revised, taking the principle of minimality into consideration in \$2.3. In addition, the assumption that schwa loss precedes 
OSL as a trigger of this process is not well-supported, as will be discussed in \$1.2.2.2.1.

\subsubsection{MORAIC APPROACH}

1.2.2.1. HAYES'S 1989 ANALYSIS. Hayes 1989 analyzes OSL together with other CL processes within the framework of Moraic Phonology.

It is generally acknowledged that the mora is the weight unit. Hayes follows Hyman 1985 and McCarthy \& Prince 1986, 1988 in stating that the mora is the subsyllabic unit which counts syllable weight: a light syllable has one mora and a heavy syllable has two. Thus, in languages with contrastive vowel length, long and short vowels have the following mora structures (Hayes 1989: 256):

(4) a.

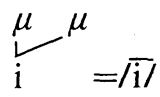

b.

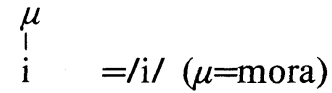

First, Hayes begins with the analysis of an ordinary CL process, observed in Latin as in 5:

(5) (i )

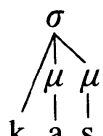

$\mathrm{k}$ a s
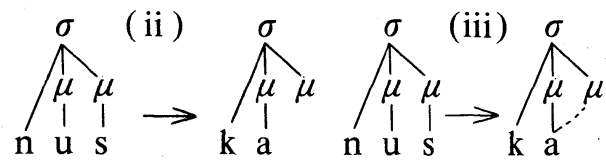

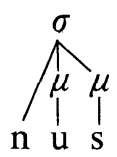

To account for CL, he postulates 6:

(6) Moraic Conservation

CL processes conserve mora count.

In 5ii, the segmental rule deletes /s/ in the first syllable. In 5iii, the empty mora position is preserved by virtue of 6 and is filled by /a/ by spreading.

The analysis of OSL in ME runs as follows:

(7) ( i )

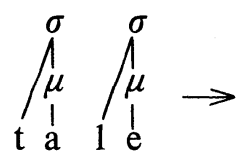

(iv)

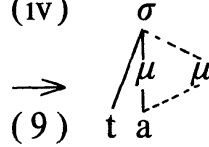

(ii)

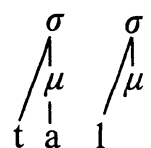

( v )

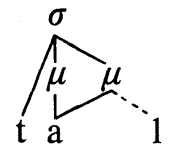

$\stackrel{\text { (iii) }}{\rightarrow} \int_{\substack{\mu \\ 1}}^{\sigma} \mu$

In 7ii, schwa is deleted. In 7iii, Parasitic Delinking in 8 delinks $/ 1 /$ from the syllable structure.

(8) Parasitic Delinking

Syllable structure is deleted when the syllable contains no 
overt nuclear segment.

In 7iv, spreading comes into operation as stated in 9.

(9) CL in Middle English (Hayes 1989: 269)

Fill empty moras by spreading from the left.

$7 \mathrm{v}$ is the last stage at which word-final / $1 /$ is adjoined to the syllable structure by virtue of a principle whereby all prosodic structure is constructed maximally, which is observed in Hayes 1980/1, Prince 1985, Ito 1986, etc. (cf. 47 and some related problems to be discussed later).

Hayes's analysis contains two problems, concerning (i) the trigger of OSL, and (ii) the mechanism of OSL, or of more general CL processes. In the following, we will discuss each problem.

\subsubsection{Problems of hayes'S ANALYsis.}

1.2.2.2.1. THE TRIGGER OF OSL. Hayes follows Minkova 1982, 1985, who assumes that schwa loss is the trigger of OSL. Minkova (1985: 165) claims that 'one very convincing piece of evidence is the unquestioned geographical parallelism of two changes: both of them [i.e. schwa loss and OSL] start in the North.'

However, the fact that both changes start in the North does not necessarily imply that schwa loss is the trigger of OSL. As Jordan $(1974, \S \$ 141$, 290) states, OSL occurred in the twelfth century in the North and in the thirteenth and fourteenth centuries in the rest of the dialects, while schwa loss takes place one century later in each case. (Cf. also Mossé (1979, §\$19, 36) among others.)

Our analysis of exceptions to OSL, as regards high vowels, will show that the word-final schwa is deleted when OSL does not apply, while it is not deleted when OSL does apply. (For further details, see §3.2.1.) This means that contrary to Minkova's and Hayes's assumptions, schwa loss is not the trigger of OSL. We will rather state that the trigger of OSL is Vowel Reduction, which is one of the characteristic differences between OE and ME (Wright \& Wright 1979 §134, Mossé 1979 §§1, 34-6, Jordan $1974 \$ \$ 133-4)$.

1.2.2.2.2. ThE MECHANISM OF CL. Hayes's argument is summarized as follows:

(10) (i ) CL is subject to prosodic constraints. Only languages that have a syllable weight distinction allow CL.

(ii) CL (=spreading) occurs immediately following every deletion rule. $\mathrm{CL}$ is an automatic consequence of the 


\section{deletion.}

(iii) The spreading operations have the effect of licensing empty moras. Otherwise, empty moras are deleted by Stray Erasure.

As for 10i, if Vowel Reduction turns out to be the trigger of OSL, the mechanism of OSL goes as follows:

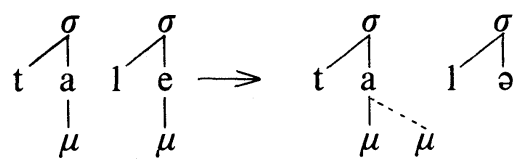

which leads us to assume that 'syllable weight distinction' should be replaced by 'weight distinction in metrical structures' in $10 \mathrm{i}$. In $\$ 2$ we will claim that 'only Quantity Sensitive (QS) languages, in which a heavy syllable is forbidden on the weak side of a foot, allow CL, and will further show that such a metrical system is represented by means of grid constituent structures.

According to Hayes (1989: 263-4), 10ii is asserted to be a natural consequence if it is assumed that CL rules form part of a syllabification principle. However, the relationship that CL rules have with Resyllabification is not considered in detail.

Regarding 10iii, the primary answer as to what induces spreading (= CL) rather than Stray Erasure is not given. ${ }^{3}$

In the following sections, we will attempt to account for the mechanism of OSL in ME, resolving the problems raised here.

\section{Phonological Representations.}

2.1. TwO-PROSODIC-PLANE THEORY-SYLLABLE PLANE AND GRID PLANE. ${ }^{4}$ The phonological representations are given in 12, in which the syllable plane and the grid plane are separately represented, together with the melody plane. By assuming such representations we can distinguish the

${ }^{3}$ In the previous analyses, Hermans (1985: 239-44) and Clements (1986: 43) insert empty slots to explain CL. Although Hermans (1985: 261) further observes that rules of this type may only apply in stressed syllables, it is a mere stipulation.

${ }_{4}$ The implicit assumption made in Metrical Phonology has been that syllable structures are a lower constituent of foot structures on the same plane. As far as I know, Clements \& Keyser 1983 first propose the nucleus display representing mora structures, which is distinguished from the syllable display. Archangeli 1984 makes a distinction between the stress plane and the syllable plane, and Halle \& Vergnaud 1987 state that the stress plane is autosegmental. However, they are not concerned with the interaction between the stress plane and the syllable plane. 
syllable weight from the metrical weight.

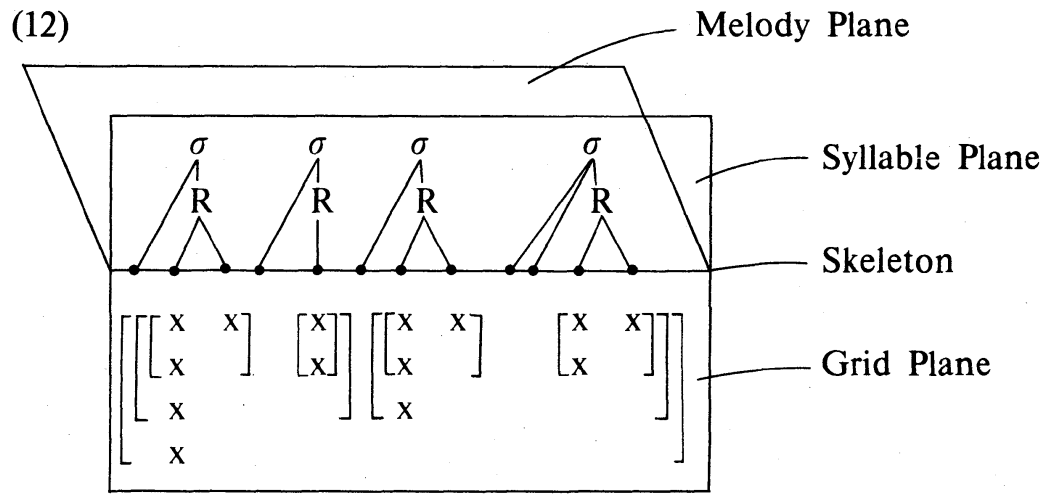

We will propose that the terminal grid elements are 'projected' from the syllable plane to the grid plane, as given in $\$ 2.2$.

2.2. Projection and Quantity Sensitivity (QS). Halle and Vergnaud (henceforth $\mathrm{H} \& \mathrm{~V}) 1987$ propose their original mechanism of constructing grid constituent structures and analyze a great many stress systems of languages. According to $\mathrm{H} \& \mathrm{~V}$, the bottom line of the grid representation (their Line 0), which is 'a sequence of abstract positions or slots associated with the stress-bearing units' ( $H \& V$ 1987: 5), is actualized by the notion of 'projection' in the sense of Hayes 1980/1. However, the mechanism of 'projection' is not explicitly stated by $\mathrm{H} \& \mathrm{~V}$ because it is taken for granted that each rime is projected as one grid element on Line $0 .^{5}$

By contrast, we follow Prince (1983: 57-60) in 'gridding heavy syllables'. Prince states that a heavy syllable in QS languages hold two grid positions, for which our analysis of OSL will provide very strong confirmation. We propose the following mechanisms of Projection:

(13) a. Projection (I): (universal)

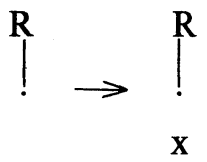

${ }^{5}$ Halle 1989 revises this by introducing MORA, but it is not explicitly stated how and why languages differ as to the choice of stress-bearing elements: the heads of a syllable nuclei or all elements in a syllable nuclei (=MORA in his terms). 
b. Projection (II): ${ }^{6}$ (language-specific) (only in QS)

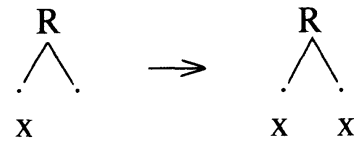

The application of $13 b$ is fed by that of 13a. Namely, both nonbranching and branching rimes are inputs to $13 \mathrm{a} .{ }^{7}$ It is $13 \mathrm{~b}$ that suggests why only heavy syllables in QS languages hold two grid positions, while any syllables in Quantity Insensitive (QI) languages hold one grid-position, irrespective of syllable weight, as shown in 14:
a. QI languages
b. QS languages
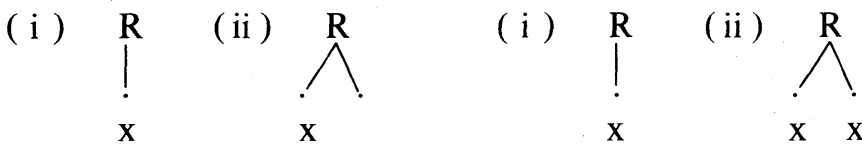

Returning to $13 \mathrm{~b}$, we follow Prince 1983 in asserting that there are language-specific restrictions, governed by sonority, as to what segments are qualified to be projected as the second grid element. Some languages choose only V, some choose $\mathrm{V}$ and $\mathrm{S}$ (=sonorants), and others choose $\mathrm{V}$, $\mathrm{S}$, and $\mathrm{C}$ (=obstruents), for example, as the inputs to Projection (II). ${ }^{8}$

2.3. Metrical tRanSformation, heAVINESS COPYing, AND Minimal FOOT PRINCIPLE. In this paper, we propose that $\operatorname{grid}(=\mathrm{x})$-delinking is regarded as Metrical Transformation, as seen in 15:

(15) Metrical Transformation-x-delinking
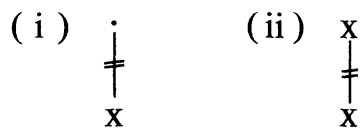

In our approach, a grid element is delinked from a skeletal slot as in $15 \mathrm{i}$,

${ }^{6}$ We assume that there is no further projection. As John McCarthy and Michael Hammond pointed out to me, three degrees of quantity are observed in Pirahã, Persian, Japanese, Eskimo, Klamath, Hindi, etc. Aside from these languages, however, the non-occurence of further projection is explainable by virtue of the hypothesis that bounded constituents are binary at most (Prince 1985) and by the Constituent Intergrity Principle, concerning 'which see Kaminashi 1989 and (in prep.).

7 Thus, 13a has nothing to do with the Linking Constraint (Hayes 1986: 331), which states that association lines in structural description are interpreted as exhausitive.

${ }^{8}$ In our approach, it is Projections (I) and (II) on the grid plane that assign the MORA (in Halle's terms) to rime segments. 
or from the lower grid element as in 15ii. We will show that it is $15 \mathrm{i}$ that is involved in OSL.

$\mathrm{X}$-delinkings derive the following representations:

(16) Derived representations

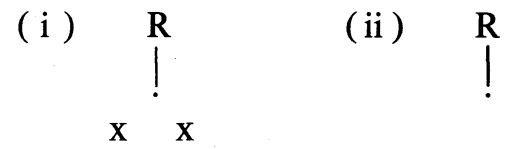

(Weakened vowel)

16ii is the structure of a weakened vowel, such as a schwa. In short, (partial or complete) feature delinking takes place when the rime does not hold a grid element. When feature delinking is complete, the default vowel (/ə/ in ME) is inserted later in the derivation. ${ }^{9}$ (Cf. 25 and 26 for the formulations of Vowel Reduction.)

16i contains the extra grid element which is delinked from a skeletal slot and is moved to this position. When $16 \mathrm{i}$ is derived, Heaviness Copying in 17 applies, because no language treats a nonbranching rime as heavy in the metrical structure. ${ }^{10}$

(17)

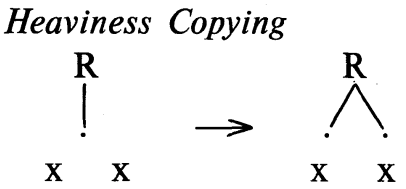

The fact that the delinked grid element is not deleted, ${ }^{11}$ inducing Heaviness Copying 17, is attributed to the Minimal Foot Principle in 18:

(18) Minimal Foot Principle

A grid-deletion may not take place in a minimal foot which is the head of the immediately higher constituent. (Parameter as to the higher constituent: Fj, Word, etc.)

9 Borowsky (1986: 151) and Halle \& Mohanan (1985: 82, 83) also assume that Vowel Reduction is a process whereby the feature matrix is deleted. On the other hand, Hyman $(1985: 8,59)$ regards schwa in Chuvash and Chitimacha as weightless. French should be included in these examples, as John McCarthy pointed out to me. In our analysis, schwa in ME has both characteristics noted by Borowsky, Halle \& Mohanan, and Hyman.

${ }^{10}$ Dealing with Eastern Cheremis in which full vowels contrast with reduced vowels, Hayes (1980/1: 57-8) suggests that there is an underlying vowel length contrast, VV and V. This being the case, Eastern Cheremis is no longer considered an exception.

11 The delinked grid is deleted otherwise, due to Stray Erasure (Steriade 1982), which follows from Prosodic Licensing (Ito 1986) stating that 'all prosodic units must be prosodically licensed, i.e. belong to higher prosodic structure (modulo extraprosodicity).' 
18 plays a crucial role in explaining OSL. This principle owes a great deal to McCarthy \& Prince's 1986, 1988 notion of Minimal Word (i.e. one of prosodic templates) composed of bimoraic units, by means of which various morphological processes are explained systematically in Prosodic Morphology. ${ }^{12}$

With the parameter being set, the Minimal Foot Principle in ME goes as follows:

(19) Minimal Foot Principle in ME

A grid-deletion may not take place in a minimal foot which is the head of $\mathrm{Fj}^{13}$

In this paper we will show that the Minimal Foot Principle in 19 and Minimal Word Principle to be presented in $\$ 4$ are crucial in explaining OSL in ME. These two principles should be distinguished from each other, since the former operates on the grid plane and the latter on the syllable plane.

2.4. GRID CONSTITUENT CONSTRUCTION RULES IN ME. We propose that metrical structures in (OE and) ME are constructed by the following rules:

(20) Grid Constituent Construction Rules in (OE and) $M E$

(i ) Apply Projections (I) and (II).

Projection (I): universal

Projection (II): language-specific

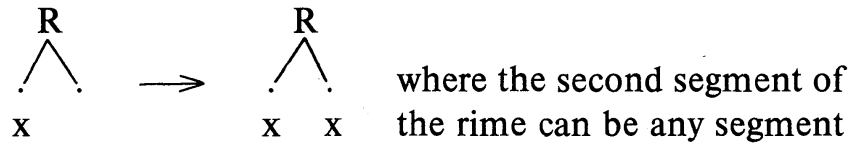

A word-final consonant is extrametrical.

(ii) Form constituents on $\mathrm{x}$. (Fi-construction)

Parameter settings: binary, left-headed, left to right

12 According to McCarthy \& Prince, Minimal Word also serves as a well-formedness condition in phonology, blocking a vowel from being deleted in bimoraic words, or inducing a vowel to be inserted into monomoraic words.

${ }_{13}$ Although we cannot analyze them in this paper, OSL takes place in secondary stressed syllables, as in cháffà̀re, físcę̀̀re, lếdę̀re, nýhtyngàle, ánswę̀re, áwrę̀̀ke, bístę̀re, etc. (Nakao 1985: 131-2). This implies that x-deletion in a minimal foot is blocked in a head $\mathrm{Fi}$ of $\mathrm{Fj}$ rather than that of a Word in ME. In languages with only one foot level, the parameter is set, so that $\mathrm{x}$-deletion is surely blocked in a head foot of a Word. 
(iii) Form constituents on Fi. (Fj-construction)

Parameter settings: binary, left-headed, right to left

(iv) Form a constituent on $\mathrm{Fj}$. (Word-construction)

Parameter settings: unbounded, left-headed

As 20 shows, after Projections (I) and (II), constituents of the higher levels are constructuted on the lower constituents themselves. We propose two types of foot structures, the minimal foot $\mathrm{Fi}$ and the larger foot $\mathrm{Fj}$. Fi-construction accounts for the equivalence between one heavy syllable (CVC, or CVV) and one light syllable followed by an unstressed syllable (e.g. CVCV) in OE, which is gradually lost in ME. (Further details on OE stress are given in Kaminashi 1989.)

3. OSL IN DISYLLABIC WORDS.

3.1. General MeChANISM-OSL IN NON-HIGH vowels. The following exemplifies how OSL takes place:

(21)
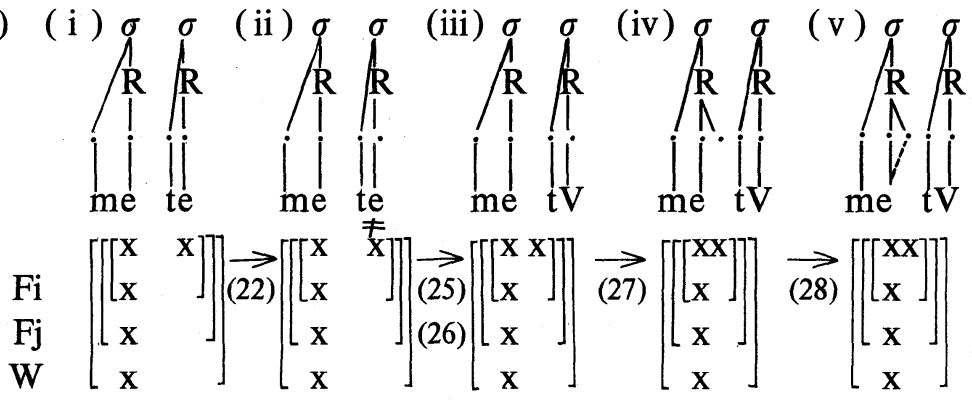

$\left.\begin{array}{c}F i \\ F j\end{array}\right]\left[\left[\begin{array}{l}x \\ x \\ x \\ x\end{array}\right.\right.$

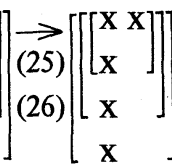

$\overrightarrow{(27)}\left[\left[\begin{array}{c}x x \\ x \\ x \\ x\end{array}\right]\right]$

(V: default vowel)

In 21ii, $\mathrm{x}$-delinking in 22 applies:

(22) $x$-delinking

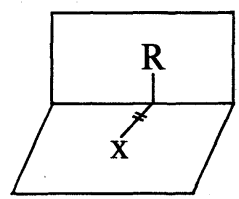

In 21iii, the delinked grid element is not deleted, but is moved to the word-initial syllable by 23 , so deriving the ill-formed structure $16 \mathrm{i}$ :

(23) Condition on Grid Movement

The delinked grid element moves to the sister position in the constituent.

which is regarded as a very general condition on grid movement, explaining stress shifts generally (cf. Al-Mozainy, Bley-Vroman, \& McCarthy 
1985 , among others). In 21iii, in spite of the fact that the sister position (i.e. the first skeletal slot, here) of the constituent has already been filled by a grid element, the delinked grid element must move to that position, as in 24, which is due to the Minimal Foot Principle in 19.

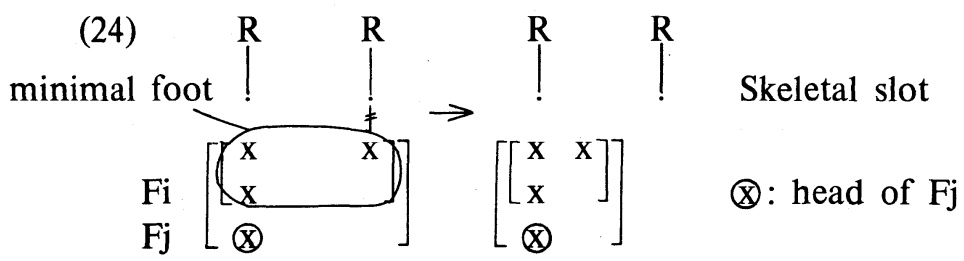

Losing the grid element, the vowel in the second syllable undergoes Vowel Reduction which is composed of two processes: feature delinking in 25 and $/ \partial /$-insertion in 26 :

(25) Feature delinking

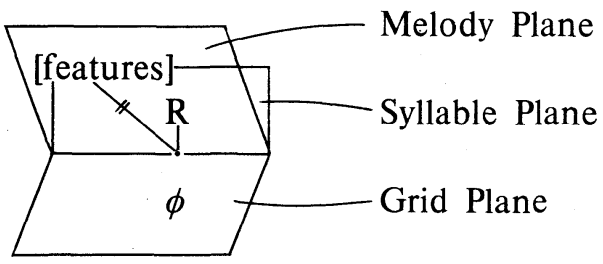

(26) $/ 2 /$-insertion

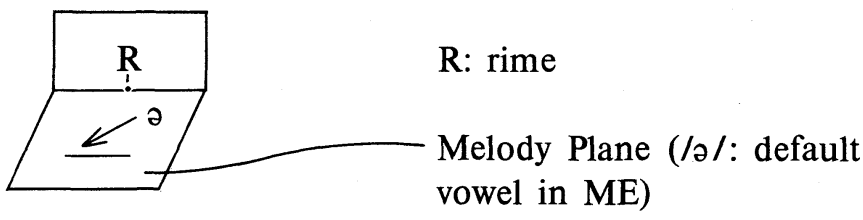

We will be concerned with / $/$ /-insertion again, dealing with exceptions to OSL in 3.2.3.

In 2liv, Heaviness Copying in 27 applies in the first syllable in order to remedy the ill-formed structure:

(27) Heaviness Copying

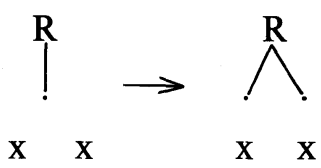

In $21 \mathrm{v}$, spreading occurs as 28 states and OSL is brought into completion:

(28) In ME, spreading takes place from the left. 


\subsection{EXCEPTIONS TO OSL.}

3.2.1. SONORITY-SENSITIVE RESYLLABIFICATION (I). The first exception to OSL is given in $29 \mathrm{~b}$ :

(29) a. give $>$ gẹve, gives $>$ gẹves, stire $>$ stệre (North)

b. give $>$ gif, gives $>$ gives, stire $>$ stir

In 29a the examples in which OSL applies in the North are given, whose mechanism is identical to 21 . On the other hand, the examples in $29 \mathrm{~b}$ are those in which OSL does not apply in the remaining dialects. The sample derivation goes as follows:

(30)
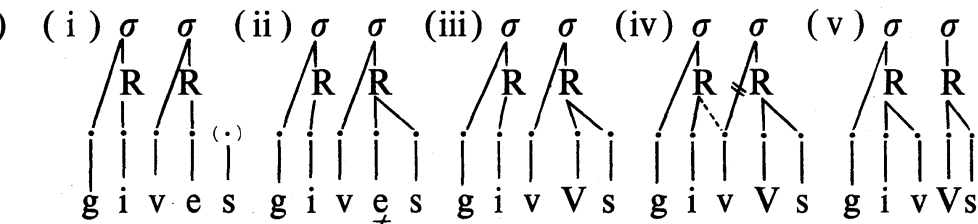

$F i$
$F j$$\quad\left[\int \begin{array}{l}x \\ x \\ x \\ x\end{array}\right.$

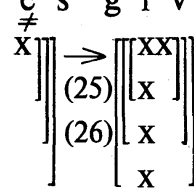

$\overrightarrow{(31)}\left[\left[\begin{array}{c}\mathrm{Xx} \\ \mathrm{x} \\ \mathrm{x} \\ \mathrm{X}\end{array}\right]\right.$

$\rightarrow\left[\left[\begin{array}{c}\mathrm{XX} \\ \mathrm{X} \\ \mathrm{X} \\ \mathrm{X}\end{array}\right]\right]$

30 is identical to 21 , up to $30 \mathrm{iii}$. In $30 \mathrm{iv}$, however, instead of Heaviness Copying in 27, which is the normal procedure involved in OSL, Resyllabification (I) in 31 applies:

(31) Resyllabification (I) (=Syllable Transformation) (in Midland and South)

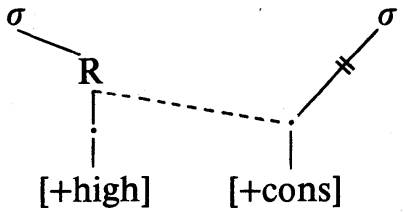

(domain: Fi)

which shows the reluctance of lengthening of high vowels, which are less sonorous than the other vowels. ${ }^{14}$ When high vowels have the structure in 16i, Resyllabification (I) applies, so as to bleed Heaviness Copying and the subsequent spreading, as shown in 30 .

32 is the case in which $\sigma$-delinking in 33 applies at the last stage:

${ }^{14}$ In Swedish OSL, the consonants /p, t, k, s/ are geminated if the preceding vowel is non-low (Árnason 1980: 73). According to Weinstock $(1975: 764,768)$, lower vowels tend to be lengthened more often than higher vowels in Homorganic Lengthening, which can also be seen as a CL process, in some dialects of Danish and Swedish. 


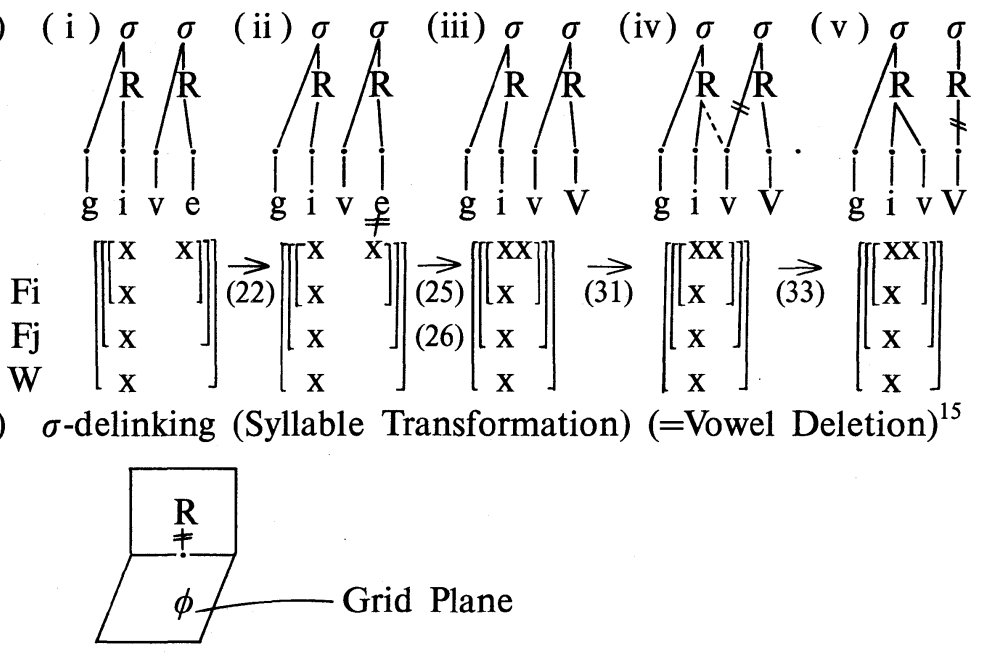

$\sigma$-delinking in 33 applies obligatorily when the rime has no onset nor any coda, which accounts for the description made by Mossé $(1979, \S 36)$ : (34) ...e was dropped in words of two or three syllables and first in disyllables with short radical vowel: sone 'son' became son [sune $>$ sun $ə>$ sun] in a period when tăle 'tale' was still pronounced in two syllables [ta'lə]. (underlining mine).

3.2.2. SONORITY-SENSITIVE RESYlLABIFICATION (II). In the following, we are concerned with the second exceptions to OSL:

(35) []$_{\sigma}[\mathrm{SV}(\mathrm{C})]_{\sigma}^{\#}$ (S: sonorants)

merisc 'marsh' warop 'warth' welisc 'Welsh' weoloc 'whelk' heorot 'hart' hænep 'hemp'

(36) []$_{\sigma}[\mathrm{GV}(\mathrm{C})]_{\sigma}^{\#} \quad$ (G: underlying glides)

twiges $>$ twies 'twice' clawu $>$ clawe 'claw'

dagas $>$ dawes 'days' dragan $>$ drawen 'draw'

The data in 35 and 36 are respectively optional and obligatory exceptions to OSL. ${ }^{16}$

15 Concerning the conditions of application of 33 , see 45 and 53.

16 As Toshio Nakao pointed out to me, the process observed in 36 occurred chronologically earlier than OSL. We assume that the synchronic grammar of ME contains Resyllabification (II), to be presented in 40 . 
In 36, the palatal, labio-velar, and velar fricatives in the onset are regarded as underlying glides which are strengthened at the position of the onset. ${ }^{17}$ That is, we state that the high vowels, the glides, and the corresponding voiced fricatives have the following distributions in the syllable:

$$
/ \dot{\mathrm{g}}, \mathrm{\gamma}, \mathrm{w} / \sim / \mathrm{j}, \mathrm{w} / \sim / \mathrm{i}, \mathrm{u} / \text { alternations in the syllable }
$$

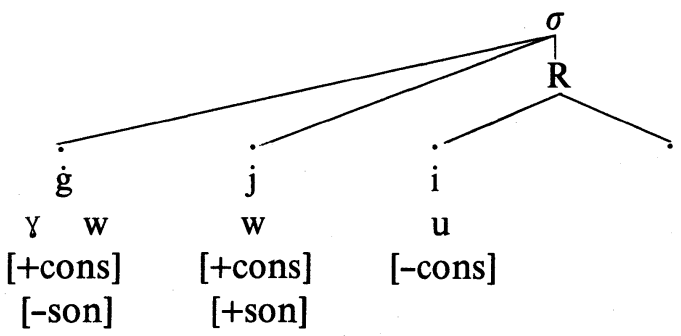

We assume that there are two kinds of surface high vowels: one has the underlying specification [-cons], so that it is always associated with the rime-initial position; the other has the underlying specification [+cons], so that it has the surface alternations as given in 37 . When it holds the onset-initial position, it may surface as a palatal, a velar, or a labio-velar fricative. When Syllable Transformation induces it to hold the rime-initial position, it must surface as a high vowel, changing its consonantality to [-cons]. Otherwise, it may stay as a glide.

38 and 39 illustrate how OSL does not take place in 35 and 36:
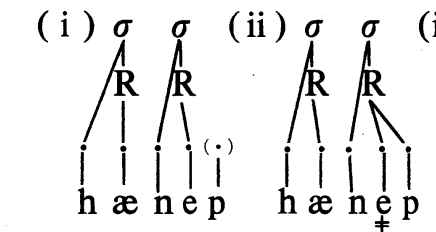

(iii)

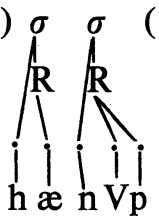

(iv)

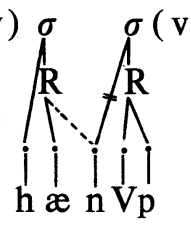

$\prod_{h æ n} \prod_{i=1}^{R}$
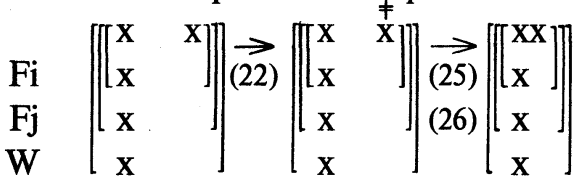

$\overrightarrow{(40)}\left[\left[\begin{array}{c}\mathrm{Xx} \\ \mathrm{x} \\ \mathrm{X} \\ \mathrm{X}\end{array}\right]\right.$

$\rightarrow\left[\left[\begin{array}{c}x \\ x\end{array}\right] \|\right.$

${ }^{17}$ A similar analysis of Spanish glides is given in Harris 1983. 
(39)

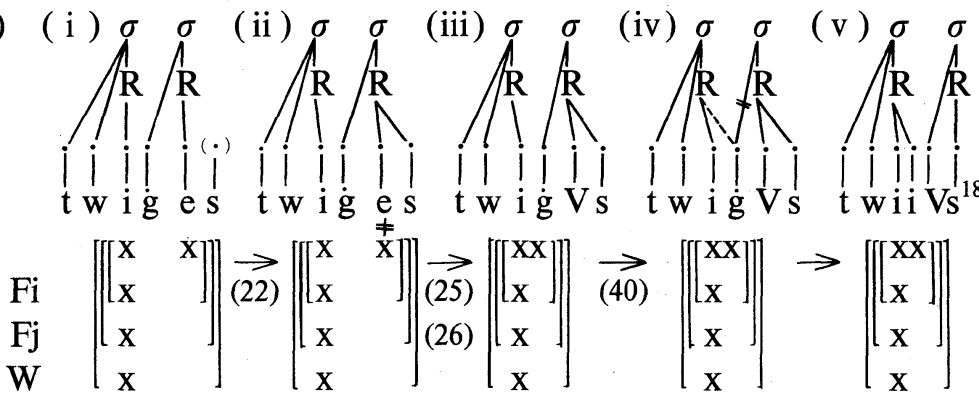

In 38ii and 39ii, x-delinking 22 applies. In 38iii and 39iii, Vowel Reduction composed of 25 and 26 takes place. In 38iv and 39iv, the following Resyllabification applies:

$$
\text { Resyllabification (II) (Syllable Transformation) }{ }^{19}
$$<smiles>[X]C([R]O)[Y]I</smiles>

$\mathrm{R}$ : rime

when $\mathrm{X}=$ glides, it is obligatory

$\mathrm{X}=$ liquids or nasals, it is optional (domain: $\mathrm{Fj}$ )

The occurrence of 40 is attributed to too close a sonority difference between the sonorant segment in the onset and / $/$ in the rime. ${ }^{20}$

40 bleeds Heaviness Copying and the subsequent spreading. It is only when 40 does not occur that OSL takes place.

${ }^{18}$ In twiiVs, two /i/s differ in the consonantality. Later, the following reanalysis occurs:

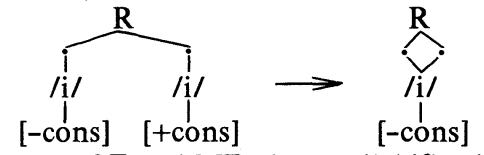

${ }^{19}$ Between OE and ME, the resyllabification of $/ \dot{\mathrm{g}}, \gamma, \mathrm{w} /$ after long vowels caused vowel shortenings as follows:

OE sægản $>$ seien plōgas $>$ plowes blōwan $>$ blowen

which clearly show that $/ \dot{\mathrm{g}}, \gamma, \mathrm{w} /$ are resyllabified by 40 . A similar resyllabification is assumed to take place in present-day English as well (cf. Borowsky 1986: 291-2).

${ }^{20}$ A question raised by Norio Yamada reminded me of the Minimal Sonority Difference (Harris 1983, Steriade 1982, Selkirk 1984 etc.). As one of the EL reviewers pointed out to me, though, the Minimal Sonority Difference in the previous analyses takes only consonant clusters into consideration. We broaden its use, so as to deal with all sequences in the syllable structure (cf. Kaminashi 1987). The theoretical interpretation of the difference in sonority between vowels and $/ \partial /$ and its effect in phonological processes are given in Kaminashi (in prep.). 
3.2.3. $\sigma$-DELINKING (FOLLOWED BY STRAY SEGMENT ADJUNCTION), 41 and 42 are the exemplary data of the last type of exceptions to OSL:

(41) []$_{\sigma}[\mathrm{CVS}]_{\sigma}^{\#}$ (S: sonorants) copor $>$ coper, copre ${ }^{21}$ 'copper' $\mathrm{fe}(\mathrm{o})$ tor $>$ feter, fet(t)re 'fetter' fetel $>$ fetel, fetle 'fettle' seofon $>$ sefen, sefne 'seven'

(42) []$_{\sigma}[\mathrm{CVG}]_{\sigma}^{\#}$ (G: underlying glides) belig $>$ bely, popig $>$ popi, penig $>$ peni, manig $>$ mani, hefig $>$ hevi, stedig $>$ stedi

The data in 41 are optional exceptions and those in 42 are obligatory exceptions to OSL. Here follows the sample derivation of 41:

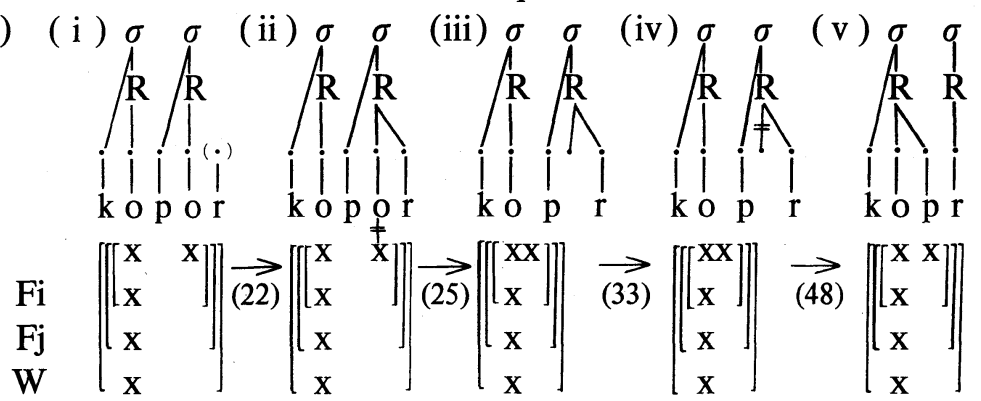

After x-delinking 22 applies in 43ii, Vowel Reduction (=feature delinking 25 and /ə/-insertion 26) applies optionally in 43iii. Its optionality comes from that of $/ \partial /$-insertion. Thus, we revise 26 into 44 whereby the frequency of $/ \partial /$-insertion is stated as depending on the sonority of the segment in the same rime:

(44) / / /-insertion (revised)

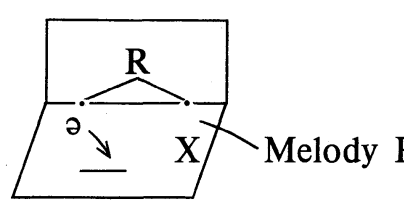

$\mathrm{R}$ : rime

when $\mathrm{X}=$ underlying glides, it does not occur

$\mathrm{X}=$ sonorants, it is optional

$\mathrm{X}=$ obstruents, it is obligatory

In 43iv, since / / /-insertion 44 does not apply, $\sigma$-delinking 33 takes place automatically as stated in 45 :

(45) $\sigma$-delinking 33 takes place automatically when /ə/-insertion does not take place.

${ }^{21}$ From the spelling copre we may perhaps be able to infer that the /r/ was already syllabic at that time. 
Without the obligatory rime position in the syllable structure, the syllable structure itself is deleted. Thus, the stray segment $/ \mathrm{p} /$ is adjoined to the preceding syllable by the Stray Segment Adjunction 46, whose occurrence follows from the Maximality Principle in 47:

(46) Stray Segment Adjunction ${ }^{22}$

Adjoin unsyllabified segments to the adjacent constituent.

(47) Maximality Principle (Prince 1985: 471)

Units are of maximal size, within the other constraints on their form.

In $43 \mathrm{v}$, the word-final sonorant becomes syllabic by 48 :

(48) Sonorant Syllabification

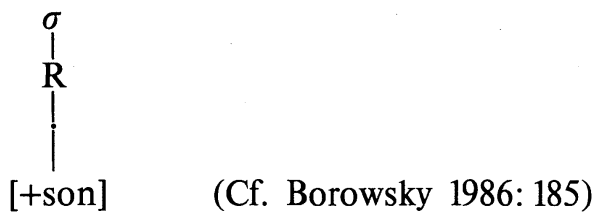

As concerns 42 , by referring to the alternations of $/ \dot{g} / \sim / j / \sim / \mathrm{i} /$ in the syllable in 37 , we present the following derivation:

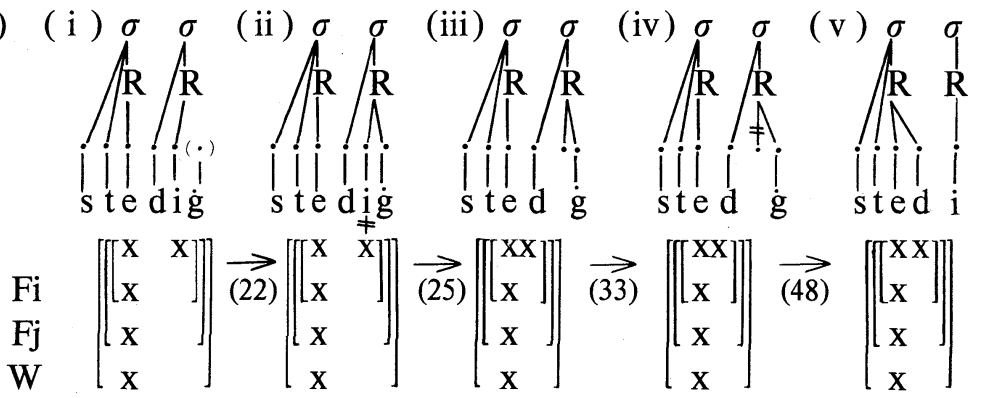

In $49 \mathrm{i}$ an underlying glide $/ \mathrm{j} / \mathrm{is}$ realized as $/ \mathrm{g} /$ word-finally. In 49ii, $\mathrm{x}-$ delinking 22 applies. In 49iii, after the application of feature-delinking $25, / \partial /$-insertion is blocked obligatorily because the slot in question is followed by an underlying glide, as 44 states. Since /ə/ is not inserted in $49 \mathrm{iv}$, the rime node is delinked by 33 automatically, as stated in 45 . The stray segment $/ d /$ is adjoined to the preceding syllable by the Stray Segment Adjunction in 46 . In $49 \mathrm{v}, / \mathrm{g} /$ is vocalized, being associated with the rime by 48 and changing its consonantality to [-cons] by virtue of 37 .

${ }^{22}$ Irrespective of the sonority of an adjoined segment, Stray Segment Adjunction always bleeds Heaviness Copying. 
3.3. SUMmary. In $\S 3$, we have analyzed the occurrences and nonoccurrences of OSL in disyllabic words. We have asserted that the trigger of OSL is Metrical Transformation, i.e. x-delinking 22, and that the occurrence of OSL follows from the Minimal Foot Principle in ME in 19.

As we noted in 2.4, Fi-construction accounts for the equivalence of heavy syllables (CVC and CVV) to one light syllable followed by an unstressed one (e.g. CVCV), which is also attested in OE verses, and is known as 'resolution' (Bliss 1958: 27, Kuryłowicz 1948/9: 36, Nakao \& Ono $1980: 545)$. In our analysis, the loss of 'resolution' in ME verses is regarded as the empirical evidence that $\mathrm{x}$-delinking 22 is applied to the second syllable of words. ${ }^{23}$ Thus, the second syllables get reduced in $\mathrm{ME}^{24}$

Moreover, the nonoccurrence of OSL in loanwords from French as in potel 'pottle', cofin 'coffin', fagot 'faggot', roket 'rocket' etc. (Bliss 1969) is attributed to the failure of the application of x-delinking 22. Namely, in Old French primary stress falls on the word-final syllable (Evert 1969, §146), so that $\mathrm{x}$-delinking 22 cannot apply to these words. ${ }^{25}$

These facts serve as the evidence that $\mathrm{x}$-delinking 22 is the essential trigger of OSL. ${ }^{26}$

The Minimal Foot Principle keeps the delinked grid element from being deleted in the minimal head foot of $\mathrm{Fj}$, which derives the ill-formed structure 16i, so as to invoke Heaviness Copying 27. The subsequent spreading from the left in 28 derives long vowels.

${ }^{23}$ Thanks to one of the EL reviewers, whose comment reminded me of this fact.

24 According to Kuryłowicz (1984/9: 38) and Bliss (1962: 36), the loss of 'resolution' in ME verses is attributed to the simplification of geminates. However, word-medial geminates are not simplified at the period when OSL takes place. Otherwise, the simplified outputs /CVC.CV/ > /CV.CV/ would be inputs to OSL.

${ }_{25}$ We assume that even if the primary stress might move to the word-inital syllables by the stress rule in 20 , the second syllables still hold the second-level grid elements, so that they are immune to $\mathrm{x}$-delinking 22.

${ }^{26}$ If OSL in ME would occur without the Vowel Reduction of the second syllable, or if the second syllable bears secondary stress in the outputs of OSL, our analysis would be incorrect. As for another type of OSL, see fn. 28.

${ }_{27}$ This point was suggested to me by an anonymous EL reviewer. Kiparsky's (1982: 136-7) formulation goes as follows:

Rules A, B in the same component apply disjuctively to a form $\phi$ if and only if

(i) The structural description of A (the special rule) properly includes the structural description of $B$ (the general rule)

(ii ) The result of applying $\mathrm{A}$ to $\phi$ is distinct from the result of applying $\mathrm{B}$ to $\phi$ In that case, $A$ is applied first, and if it takes effect, then B is not applied. 
The exceptions to OSL occur due to the following condition:

(50) Heaviness Copying is a default mechanism, preceded by Syllable Transformations.

which ensures that the Syllable Transformations (i.e. sonority-sensitive Resyllabifications (I) in 31 and (II) in 40, and Stray Segment Adjunction) precede Heaviness Copying, which is explainable by virtue of the Elsewhere Condition (cf. Kiparsky 1982). ${ }^{27}$ This is why OSL does not take place when Syllable Transformation occurs. ${ }^{28}$

4. NONOCCURRENCE OF OSL IN POLYSYLLABIC WORDS- $\sigma$-DELINKING AND MINIMAL WORD PRINCIPLE IN ME. In words of more than two syllables, OSL does not take place even if x-delinking applies, as exemplified in $51 .^{29}$

(51) a. mynecene $>\min \phi$ chene $>$ minchen $\phi$ 'nun'

hereberge $>$ her $\phi$ berwe $>$ herber $\phi$ 'harbour' panone $>$ pan $\phi$ ne 'thence'

b. gader + ode $>\operatorname{gad} \phi$ rode $>\operatorname{gadrod} \phi$ 'gather, Pret. 1st, 3rd Sg' hafoc + as $>$ hav $\phi$ kes 'hawks' fæder+as $>$ fæd $\phi$ res 'fathers'

The data in 51 are subdivided into two: (a) monomorphemic words and (b) words with an inflectional suffix. In both cases, x-delinking 22 and $\sigma$ delinking 33 apply. Note the following derivation of gaderode $>\operatorname{gad} \phi$ rode $>\operatorname{gadrod} \phi$ :

${ }^{28}$ As Donka Minkova and Haruo Kubozono also pointed out to me, there is another type of OSL which is not related to the Vowel Reduction of the second syllable, as in Scandinavian languages, like Swedish (gáta>gáta [gín:t $\mathrm{t}^{\mathrm{h}} \mathrm{a}$ 'road' (Árnason 1980)). For the lack of space, we cannot discuss this type of OSL, but it is also explainable by means of the Minimal Foot Principle (cf. Kaminashi (in prep.)).

${ }^{29}$ In contrast, when disyllabic counterparts exist as words, the outputs of OSL are observed in words of more than two syllables, as follows:
a. ofer >⿳亠ेver 'over'
stede>stęe
b. Q Qvercome 'overcome'
stędefast 'steadfast'
stędefastliche 'steadfastly'

The occurrences of OSL in (b) are explainable, by positing 'word-cycle' (Borowsky 1986), which is a cycle of the unaffixed form entering level 2 . The attachments of the derivational suffixes, such as /ful/, etc., at cycle 2 of level 2 do not preclude the occurrence of OSL.

Following Halle \& Mohanan 1985, though, Kaminashi (in prep.) asserts that Word level is non-cyclic, preceding level 2. 
(52)

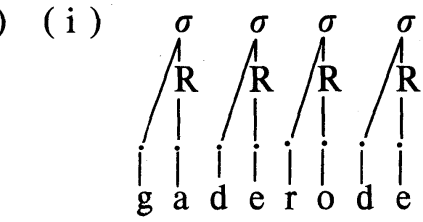

$\mathrm{Fi}$
$\mathrm{Fj}$
$\mathrm{W}$$\quad\left[\left[\begin{array}{cc}\mathrm{X} & \mathrm{X} \\ \mathrm{X} & \\ \mathrm{X} & \\ \mathrm{X} & \end{array}\right.\right.$

(iii)

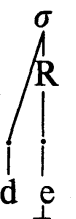

$\neq$
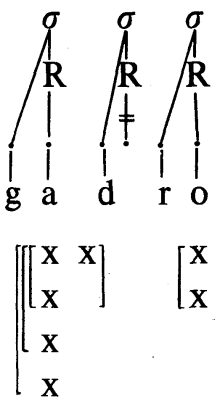

(22)

(ii)

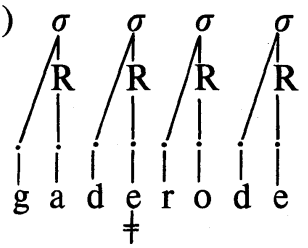

(iv)

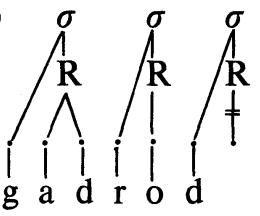

$\left[\left[\begin{array}{ll}\mathbf{X} & \mathbf{X} \\ \mathbf{X} & \end{array}\right]\left[\begin{array}{l}\mathbf{X} \\ \mathbf{X}\end{array}\right]\right]$

We are concerned only with the word-initial two syllables /gade-/ in 52 . In 52ii, x-delinking 22 affects the antepenultimate syllable /de/. In 52iii the Minimal Foot Principle 19 keeps the delinked grid element of the syllable from being deleted. However, before the delinked grid element moves to the word-initial syllable, so as to trigger Heaviness Copying, $\sigma$ delinking 33 and the subsequent Stray Segment Adjunction 46 apply in 52iii and 52iv respectively. For this reason, OSL has no chance to apply in the data of 51. Thus, we put forth 53, which states the unmarked situations:

(53) $\sigma$-delinking 33 may be automatic after x-delinking 22 .

Given 53, we find it necessary to account for the reason $\sigma$-delinking 33 does not apply in disyllabic words, contrary to 53, so that OSL may occur. We explain this fact by postulating the following principle:

(54) Minimal Word Principle in ME $\sigma$-delinking 33 may keep 2-syllable words intact. ${ }^{30}$ In disyllabic words, the Minimal Word Principle on the syllable plane

30 This principle is lost in Modern English, when the word-final schwa is deleted in disyllabic words. 
overrides 53, keeping $\sigma$-delinking 33 from occurring, and the Minimal Foot Principle on the grid plane invokes Heaviness Copying, which leads to the occurrences of OSL.

5. Conclusion. In this paper we have asserted that OSL in ME consists of Metrical Transformation (=x-delinking, which is reflected as Vowel Reduction), Heaviness Copying and subsequent spreading, within the framework of 'Two-Prosodic-Plane Theory.'

We have asserted that the Minimal Foot Principle triggers the occurrence of Heaviness Copying, which is specific to QS languages with Projections (I) and (II). Thus, it follows that CL processes, including OSL, occur only in QS languages, ${ }^{31}$ when the grid element is delinked from the skeletal slot in the minimal head foot of the immediately higher constituent.

Spreading is regarded as an automatic syllabification, ${ }^{32}$ a consequence of Heaviness Copying. However, exceptions to OSL occur since Heaviness Copying is no more than a default mechanism preceded by Syllable Transformations (e.g. Resyllabifications (I) and (II), and Stray Segment Adjunction).

Lastly, we have been concerned with the nonoccurrence of OSL in polysyllabic words. We have suggested that $\sigma$-delinking 33 is automatic after x-delinking 22 in unmarked cases. It follows that the Minimal Word Principle on the syllable plane plays an important role in explaining OSL in disyllabic words.

Thus, we have asserted that the occurrences of OSL in ME follow from (i) the Minimality Principles on two prosodic planes: the Minimal Foot Principle on the grid plane and the Minimal Word Principle on the syllable plane and (ii) the interaction of Heaviness Copying with Syllable Transformations.

${ }^{31}$ Finnish 'lacks CL entirely, even though long vowels are possible and the relevant deletion processes exist' (Hayes 1989: 263). This is because Finnish is a QI language, without Projection (II) and thus Heaviness Copying. (Cf. Kaminashi (in prep.)).

32 A CL process in which spreading derives geminates (e.g. WGmc Gemination) is analyzed in Kaminashi 1989. 


\section{REFERENCES}

Al-monainy, Hamza Qublan; Robert Bley-vroman; and John McCarthy. 1985. Stress shift and metrical structure. LI 16.135-44.

ARChangeli, Diana. 1984. Underspecification in Yawelmani phonology and morphology. MIT dissertation.

Árnason, Kristún. 1980. Quantity in historical phonology. Cambridge: Cambridge University Press.

Bliss, Alan. 1958. A metre of Beowulf. Oxford: Blackwell.

- 1962. The appreciation of Old English metre. English and Medieval studies, ed. by Norman Davis and C. L. Wrenn. 27-40. London: Allen \& Unwin.

- 1969. Vowel-quantity in Middle English borrowings from Anglo-Norman. Approaches to English historical linguistics: anthology, ed. by Roger Lass, 164-207. New York: Holt.

Borowsky, Toni. 1986. Topics in the Lexical Phonology of English. U. Mass. dissertation.

Clements, George. 1986. Compensatory lengthening and consonant gemination in LuGanda. Studies in compensatory lengthening, ed. by Leo Wetzels and Engin Sezer, 37-77. Dordrecht: Foris.

- , and SAmuel KeYser. 1983. CV Phonology: A generative theory of the syllable. (Linguistic Inquiry Monographs, 9.) Cambridge, MA: MIT Press.

EVert, Alfred. 1969. The French language. London: Faber \& Faber.

GrundT, Alice. 1976. Compensation in phonology: Open Syllable Lengthening. [Reproduced by the Indiana University Linguistic Club.]

Halle, MorRIs. 1989. Respecting metrical structure. to appear in NLLT.

- , and K. P. Mohanan. 1985. Segmental phonology of Modern English. LI 16.57-116.

- , and Jean-Roger Verngaud. 1987. An essay on stress. Cambridge, MA: MIT Press.

HARRIS, JAMES. 1983. Syllable structure and stress in Spanish. (Linguistic Inquiry Monographs, 8.) Cambridge, MA: MIT Press.

HAYES, BRUCE. 1980/1. A metrical theory of stress rules. MIT dissertation. [Reproduced by the Indiana University Linguistic Club.]

- 1986. Inalterability in CV phonology. Lg. 62.321-51.

- 1989. Compensatory lengthening in Moraic Phonology. LI 20.253-306.

Hermans, Ben. 1985. The relation between aspiration and preaspiration in Icelandic. Advances in nonlinear phonology, ed. by Harry van der Hulst and Norval Smith, 237-65. Dordrecht: Foris.

Hyman, LaRRY. 1985. A theory of phonological weight. Dordrecht: Foris.

Ito, JunKo. 1986. Syllable theory in Prosodic Phonology. U. Mass. dissertation. JoRDAN, RichaRD. 1974. Handbook of Middle English grammar: Phonology. trans. by Eugene J. Crook. The Hague: Mouton.

Kaminashi, KeiKo. 1985. Open Syllable Lengthening in ME: A metrical approach. Descriptive and Applied Linguistics, Bulletin of the ICU Summer Institute in Linguistics, 8.133-44.

—. 1987. On gemination and vocalization: A non-linear approach. Historical 
studies in honor of Taizo Hirose, ed. by Toshio Nakao, 156-78. Tokyo: Kenkyusha.

- 1989. Old English stress, High Vowel Deletion, and gemination: Two Prosodic Plane Theory. Studia Linguistica 43, 77-118.

- Stress theory and phonology in Old and Middle English. (in prep.)

Kiparsky, Paul. 1982. From Cyclic Phonology to Lexical Phonology. The structure of phonological representations (Part I), ed. by Harry van der Hulst and Norval Smith, 131-75. Dordrecht: Foris.

KurYŁowicz, JerZy. 1948/9. Latin and Germanic metre. English and Germanic studies 2.33-8.

Lehiste, Ilse. 1970. Suprasegmentals. Cambridge, MA: MIT Press.

McCarthy, John, and Alan Prince. 1986. Prosodic Morphology. ms., U. Mass. and Brandeis University.

- 1988. Quantitative transfer in reduplicated and templatic morphology. Linguistics in the morning calm 2, ed. by Linguistic Society of Korea. Soul: Hanshin.

Minkova, Donka. 1982. The environment for Open Syllable Lengthening in Middle English. Folia Linguistica Historica 3.29-58.

- 1985. Of rhyme and reason: Some foot-governed quantity changes in English. Papers from the Fourth International Conference on English Historical Linguistics, ed. by R. Eaton et al., 163-78. Amsterdam: John Benjamins.

Mossé, Fernand. 1979. A handbook of Middle English. trans. by James A. Walker. Baltimore: John Hopkins Press.

NaKaO, Toshio. 1972. History of English II. (Middle English) Tokyo: Taishukan.

—. 1985. English historical phonology. Tokyo: Taishukan.

— , and Shigeru ONo. 1980. History of English I. (Old English) Tokyo: Taishukan.

- - and Michiкo Terajima. 1982. Notes on Open Syllable Lengthening in Middle English. Studies in linguistic change in honor of Kazuo Araki, ed. by Hirozo Nakano et al., 87-95. Tokyo: Kenkyusha.

Prince, Alan. 1983. Relating to the grid. LI 14.19-100.

-. 1985. Improving tree theory. BLS 11.471-90.

Selkirk, Elizabeth. 1984. On the major class features and syllable theory. Language sound structure, ed. by Mark Aronoff and Richard Oehrle, 107-36. Cambridge, MA: MIT Press.

STERIADE, DonCA. 1982. Greek prosodies and the nature of syllabification. MIT dissertation.

Weinstock, John. 1975. Quantity and labialization in the Nordic languages: An historical interpretation. The Nordic languages and modern linguistics 2., ed. by K.-H. Dahlstedt, 756-73. Stockholm: Almquist \& Winksell.

Wright, JosePh, and Mary Wright. 1979. An elementary Middle English grammar. Oxford: Oxford University Press. 